Email: population@pncampus.edu.np eJournal Site: http://ejournals.pncampus.edu.np/ejournals/ajps/

\title{
Adolescent Health: Changing Over Time in Nepal
}

\author{
Umakanta Pokhrel \\ Department of Population Studies, Prithvi Narayan Campus, TU, Pokhara, Nepal \\ Corresponding Author \& Email \\ Umakanta Pokhrel; Email: umakanta@ pncampus.edu.np
}

Article History

Submitted 26 July 2021; Reviewed 12 August 2021; Accepted 27 October 2021 DOI: https://doi.org/10.3126/ajps.vli1.43594

\section{Copyright Information: \\ Copyright 2022@ The Author(s). \\ The journal is licensed under a \\ Creative Commons Attribution- \\ ShareAlike 4.0 International \\ License. \\ (c) (i) (?) \\ Published by \\ Department of Population Studies \\ Prithvi Narayan Campus \\ Tribhuvan University \\ Pokhara, Nepal}

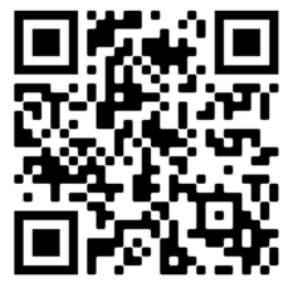

Scan to Access eJournal

\section{Abstract}

This article aims to analyse the adolescent health with changing context of demography, access and use of family planning methods and reproductive health and national policies adopted by the Nepalese government. Adolescent is complex transitional phase and equally vulnerable too due to its tender nature, furthermore advancement of technology from local level to global level challenges to adulthood greater today than ever before where they are natured throughout traditional norms, values and practices. Reports of census and periodical national level surveys show some improvement on sexual and reproductive health as a whole but in terms of bridging gap between disparities still remains significant. Though, following the guidelines of international conferences for universal excess quality reproductive health services to all it is poor to address the issues of adolescent. To meet the mandates of Nepal's policies and programmes need a broad understanding of the sexual and reproductive health as it is lower level of information in terms of places to obtain safe abortion. Adolescent has more aware about ANC and PNC but unmet need for contraception is higher than other age groups. After conditional legalization of abortion maternal mortality has decreased but still high. In contrast of government efforts to enhance CPR, it is constant over few last years. Early marriage is common in society in contrast of legal provision of lower age of marriage. Age at marriage is the most attributing factors to early sexual debut among Nepalese women. The trend of adolescent pregnancy seems to be decreasing but still exists as a great challenge to meet the target set by government. 


\section{Adolescent Health: Changing Over Time in Nepal}

Keywords: Adolescent, reproductive health, family planning, unmet need, contraceptives

\section{Introduction}

Adolescent population is facing many challenges to fulfil their sexual and reproductive health in Nepal. This is age of transition from childhood to adulthood. Generally, the term "adolescents" refers to individuals between the ages of 10-19 years (WHO/UNFPA/UNICEF, 1989 cited in MoH, 2000, p. 1). Every sixth of the world population is adolescent and though this group is considered healthy as compared to other groups but still there is substantial premature death, illness and injuries. Developing countries passing through demographic transition phase have large proportion of adolescent population (10-19 years) and despite the decreasing trend of fertility in recent years the proportion of adolescent looks like to continue for some decades. Considering the triple dividend in terms of health, countries of South East Asia are trying to address the issues of adolescent with the cooperation of WHO for the scaling up adolescent friendly health services but yet it is estimated that 1.7 million in 2015 and more than 1.1 million adolescent lost their lives in 2016 and most of the causes for it was preventable and related to their health (WHO, 2018a).

\section{Figure 1}

Adolescent health condition and issues may be changed with changing context

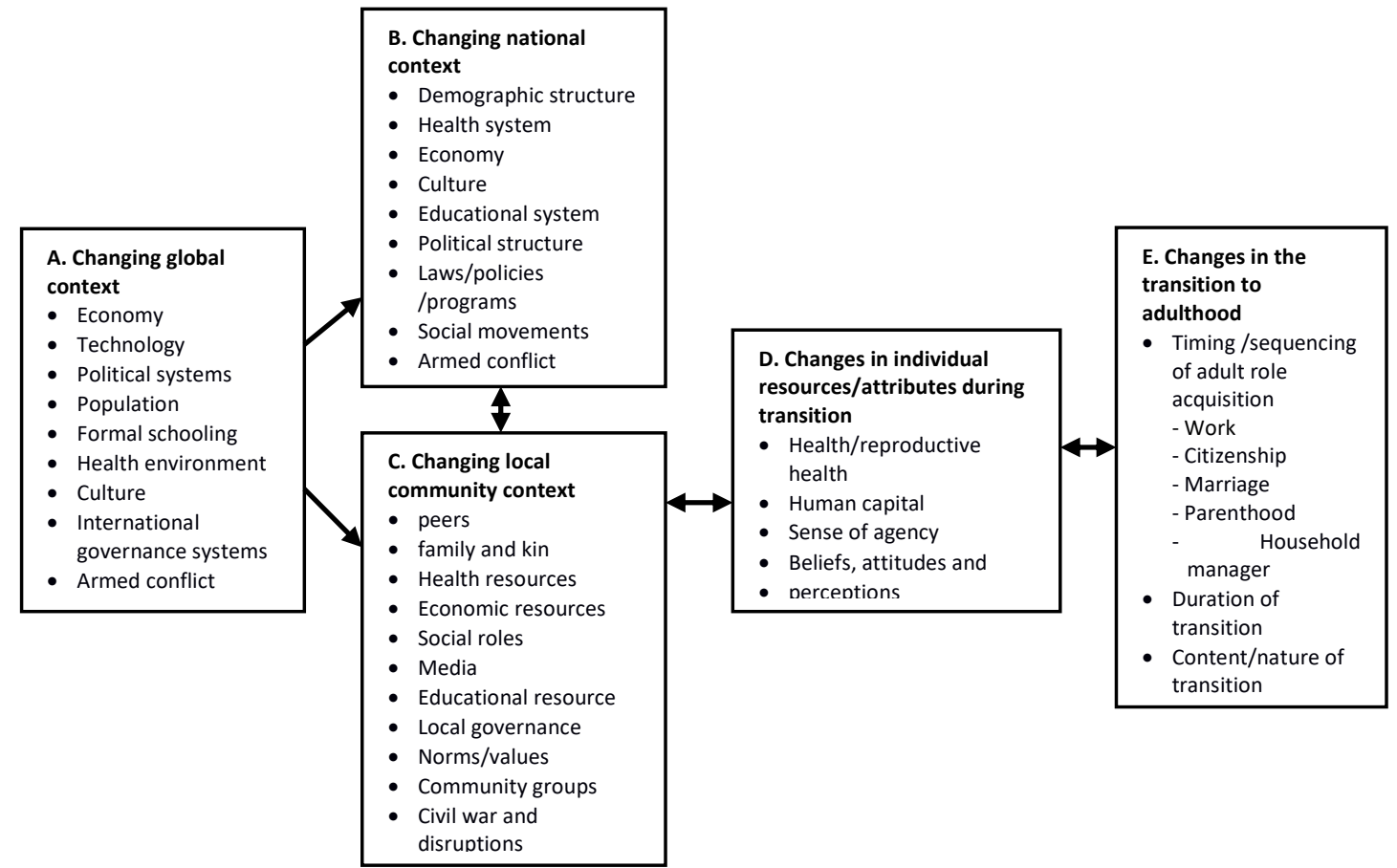

Source: (National Research Council and Institute of Medicine, 2005)

Naturally, globalization has the power to change form international level to smallest community across the national boundaries and spreading of new ideas and lifestyles through new generation can conflict with typical local norms and values and pace of progress. Adulthood itself and developing countries themselves are in transitional phase at the same time what policies and programmes are designed and what achievements are made it could be today's course of discourse for developing countries (figure 1). 


\section{Adolescent Health: Changing Over Time in Nepal}

According the report of Darroch et al. (2016), it is estimated that 21 million pregnancies had occurred in developing countries and among them about half 49 per cent unintended and more than half of them were terminated as induced abortion. More than two third abortions of this age group occur in the countries where abortion is highly restricted or prohibited. Such cases are often unsafe due to lack of proper medication facilities and it is one of the major causes of maternal death which are preventable. But the nature, scale and impacts of adolescent health needs varies between countries and within subgroups i.e. age, sex, caste and ethnicity, socioeconomic level, place of residence and geographical unit. In this context, government for effective intervention should prioritize to their actions accordingly considering the limited national resources in terms of finance and institutional.

Age at first marriage sequentially leads to the impact of met and unmet needs of family planning services, reproductive health and ultimately national future strength in terms of human resources and national progress. But still, according to the report of CBS (2015), 15.5 per cent of women aged 15-49 were first married and percentage of women who were first married or in union before 18 was 48.5. Likewise, currently married or in union percentage of women aged 15-18 years was 24.5 (Central Bureau of Statistics, 2014). It clarifies that still there are a lot of tasks to be performed for the promotion of adolescent health. Low age at marriage is not merely the life event but it carries many possible risk factors related to early motherhood, unintended birth and unsafe abortion and follows complications. In Nepal, early marriage with high unmet need of family planning services in adulthood, has accompanied with early childbearing, age specific birth rate of women aged 15-19 was 71 and 16 for aged 20-24 who had at least one live birth before age 18 .

Political commitments made in national, regional and international forums and adaptation of policies and strategies should reflect the facts of progress and it is also a way of evaluation of weakness and strength of invested resources and mechanism of service delivery institutions as well. In Nepal Prior to 2002, abortion was illegal in Nepal unsafe abortion was common and deaths from abortion related complications attributed to more than half of maternal death. Due to the conditional legal provision of abortion and availability of medical abortion with great endeavours there is a drastic decrease in maternal mortality rate (MMR), from 901 per 100,000 live births in 1990 to 258 per 100,000 live births in 2015 (WHO, 2018b). Internationally, although the country specific rate of adolescent births ranged from one to 200, it has significantly declined to 43 births per 1000 adolescents in 2000. Similar trends follow for MMR of adolescent girls ages 15-19 as well (WHO, 2021). Likewise, CPR has also plateaued over recent years yet unmet need for modern contraception especially married women aged 15-19 years living in rural and remote area has continued high. Nepal government has introduced a plan to implement free safe abortion services in public clinics with the provision of free family planning services but the women from the economically underprivileged communities are unable to utilize due to other cost associated factors such as transportation, logistics, accommodation, etc.

Like other developing countries Nepal has adopted anti-natalist population policy from the beginning of the introduction of population policy in 1950. It is shifted from fertility regulation policy focusing to the uses of family planning to control birth rate to specific mortality i.e. infant and child mortality, maternal mortality and in recent years, issues emerged in international level such as reproductive rights and inclusion and bridging gaps in disparities.

\section{Objectives}




\section{Adolescent Health: Changing Over Time in Nepal}

The main objective of this study is to overview on the changes of selected demographic indicators i.e. age at marriage, family planning, child bearing, maternal care and sexual behaviour at national level and in adolescent as its subgroup based on the national level demographic health surveys and census report over time. And its specific objectives are:

i. To examine the developing trends and possible emerging discourse of adolescent sexual behaviour with existing situation of Nepal

ii. To access the gap between the achievements made in selected indicators in national level population and adolescent in terms of sexual and reproductive health i.e. CPR, unmet need of modern contraceptives, ANC and PNC visits, birth rate.

\section{Methodology}

This article has attempted to analyse the situation of adolescent sexual and reproductive health with changing context of Nepal. This work is primarily based on secondary data derived as output of periodically conducted national level demographic health surveys (NDHS) multiple indicator cluster survey 2014 and 2019 along with census reports and regional and international contemporary references. This study is statistical analysis but descriptive in nature and discussion has mainly on population subgroup i.e. adolescent. Presenting the changing indicators of demography, family planning services, met and unmet needs of contraceptives and abortion at national level population, it has tried to shed mainly on the adolescent (15-19) as subgroup on sexual and reproductive health trends over time and status of use and unmet need of contraceptives, age at marriage and child bearing, ANC and PNC and sexual behaviour.

\section{Results and Discussion}

Adolescent health is the foundation for adult health status. And due to increasing access and uses of mass communication and social cites i.e. You Tube, Facebook, Twitter, Tik Tok, Snapchat etc. unique challenges are also emerging particularly for vulnerable adolescent and youth including those with disabilities and special needs to meeting their sexual and reproductive health. Lack of adequate health information and services, awareness about puberty, gender inequality and harmful social norms prevalent in communities can have serious implications on adolescent mother health and their offspring. The issue of adolescent child bearing and unintended birth is more serious in developing countries. WHO report shows each year approximately 12 million girls aged 15-19 years and at least 777,000 girls under 15 years give birth and at least 10 million unintended pregnancies occur in developing countries (WHO, 2021). However, universal health coverage has gained momentum in recent years with the efforts of World Health Assembly and the United Nations General Assembly for universal access to affordable and quality health care services.

National adolescent sexual and reproductive health is one to the priority programme of Family Health Division (FHD) of Nepal. Nepal has revised its National Adolescent Health and Development Strategy introduced in 2000, in 2017 to address the emerging issues of adolescent in national context. Demographically, Nepal is in transitional phase where large proportion of population is below 30 years and 24 per cent of the total population is 10-19 years according to census 2011 (CBS, 2014). This fact indicates the additional opportunities for the development as well as challenges (i.e. violence and injury, substance abuse, misuse of rocketed social sites, early marriage, premarital and extra marital sexual behaviour etc.) of vulnerable population (adolescent) in terms of sexual and reproductive health. While it has been almost universal (99.9) in 


\section{Adolescent Health: Changing Over Time in Nepal}

knowledge about contraception in Nepal, NDHS 2016 reveals that only nearly 41 per cent (40.9) of the adolescent has the information on places of safe abortion facilities.

Despite fertility rate is gradually decreasing over time as expected, it was set 2.5 birth per women by Nepal Health Sector Programme (2010-2015) and target of adolescent for fertility rate is nearly achieved it was set at 70 births per 1000 women age 15-19, still the cases of CPR is lower and unmet need for CPR is higher among adolescent in Nepal (Table 1). Increasing trend of early sexual debug, pre-marital and extra marital sexual behaviour and low level of CPR and higher level of unmet need definitely can lead to the unintended result of reproductive health of adolescent. In global context, adolescent fertility rate has declined by 11.6 over the past 20 years, however there are big differences in rate across and with the regions i.e. 0.3 for South Korea and 83 for Bangladesh" (WHO, 2020). But how far the case of unmet need of contraception, in Nepal, is notably higher among younger than older it was nearly 35 per cent for age 15-19 years though it has been decreased from 42.4 in 1996. (CBS, 2015) reports that out of 25 per cent overall unmet need of contraception 10 per cent was for spacing and 15 per cent for limitation. Younger ages are likely to have need for spacing than older but due to higher unmet need among adolescent unfortunately unsafe sexual intercourses are being turned into unintended pregnancy, probably unsafe abortion and early child bearing. The unmet need for adolescent is nearly 35 per cent. It would be expected that if it would be fulfilled or reduced, definitely adolescent fertility cases of Nepal would be very much lower than existing.

Table 1

Trends of selected demographic and family planning indicators.

\begin{tabular}{|c|c|c|c|c|c|}
\hline & 1996 & 2001 & 2006 & 2011 & 2016 \\
\hline \multicolumn{6}{|c|}{ Adolescent (15-19) Marital Status } \\
\hline Never Married & 56 & 59.7 & 67.7 & 71 & 72.5 \\
\hline 72.5Married & 43.3 & 39.8 & 32.2 & 28.8 & 27.1 \\
\hline \multicolumn{6}{|l|}{ Family Planning } \\
\hline CPR Modern Method & 26 & 35 & 44 & 43 & 43 \\
\hline CPR Unmet Need & 32 & 28 & 25 & 28 & 24 \\
\hline $\begin{array}{l}\text { CPR Modern Method for } \\
\text { Adolescent }\end{array}$ & 4.4 & 9.3 & 13.8 & 14.4 & 14.5 \\
\hline $\begin{array}{l}\text { Unmet Need of CPR for } \\
\text { Adolescent }\end{array}$ & 42.4 & 35.1 & 37.9 & 41.5 & 34.9 \\
\hline \multicolumn{6}{|l|}{ Child Bearing } \\
\hline TFR & 4.6 & 4.1 & 3.1 & 2.6 & 2.3 \\
\hline $\begin{array}{l}\text { Proportion of adolescent } \\
\text { women (15-19) started child } \\
\text { bearing }\end{array}$ & 23.9 & 21.4 & 18.5 & 16.7 & 16.7 \\
\hline \multicolumn{6}{|l|}{ Maternal Care } \\
\hline $\begin{array}{l}\text { ANC from skilled provider } \\
\text { for age } 15-49\end{array}$ & & 28 & 44 & 58 & 84 \\
\hline $\begin{array}{l}\text { ANC From Skilled Provider } \\
\text { for age } 15-19\end{array}$ & 52.9 & 59.3 & 50.8 & 63.3 & 86.8 \\
\hline
\end{tabular}

Source: Demographic Health Survey, 1996, 2001, 2006, 2011, 2016

Table 1 revealed that overall unmet need for family planning is declined from 28 per cent of 2011 to 24 per cent in 2016. But the use of modern method has been remained constraint at lower level since 2011 and it is even slightly decreased (from 44 


\section{Adolescent Health: Changing Over Time in Nepal}

per cent to 43 per cent) even than 2006. Probably, it has been contributed by increasing in traditional methods of same period. From satisfactory view point too, CBS reports show the percentage of women age 15-49 years currently married or in union who have their need for family planning satisfied with modern contraceptives method is decreased from 66.3 per cent in 2014 to 61.9 per cent in 2019 (CBS 2015; 2020).

Early sexual debut and marriage with respect to high unmet need for contraception are likely adding complexity to adolescent sexual and reproductive health. According to the report of Nepal adolescent and youth survey 2011, 11 per cent of adolescent were engaged in first sexual intercourse before age of 15 years (Ministry of Health and Population (MoHP), 2012). Likewise, Nepal demographic and Health survey 2016 shows that nearly four per cent of women and three per cent of men had their first sexual intercourse by their exact age of 15. This per cent is lower for women than their married percentage (4.1) but it is higher for their counterpart (0.3). It is evident that early marriage is the most determining factor of sexual debut for Nepalese women and emerging trend of sexual intercourse before marriage among Nepalese men. The proportion of youth males with multiple sex partners in last 12 months also increased by 5 per cent in 2006 to 10 per cent in 2016. Likewise, the use of condom at last sex of youth males if that was outside spouse declined from 77 per cent to 69 per cent (Shakya, 2018). Besides these, periodical reports of Ministry of Health and Population show considerable gaps on the level of age at marriage, use of contraception, ANC and PNC visits according to the background characteristic of respondent i.e. age, sex, educational level, place of residence, etc.

Early child bearing is relatively common in Nepal, 13.8 per cent women aged 20-24 years having had a live birth before the age of 18 and the adolescent birth rate is reported 63 per thousand. Nepal Demographic and health survey 2016 reports that women age 15-19 have more ( 11 per cent) cases of still births/ miscarriages than women age 20-34 years (Ministry of Health and Population [MoHP], 2017). Likewise, 13.1 per cent of total MMR is of less than 20 years (Nepal MMMS. 2008/09). Cases of abortion could not be expected to increase at any age groups from reproductive view point but often access and utilization of safe abortion services have positive roles for spacing, limiting and possible risky result of extra marital sexual intercourse. After the conditional legalization of abortion in 2002 in Nepal, Nepal Department of Health report (2014/15) shows that utilization of safe abortion services has plateaued over the last few years. While only 41 per cent adolescent women have the information on places to obtain safe abortion facilities. More than half maternal deaths were the result of abortion related complications occurred in major hospital prior to the legalization of abortion in Nepal. In addition to legalization of abortion, through concerned efforts of government maternal death caused of unsafe abortion reduced to seven per cent. It is still high compared to higher age groups of reproductive age and has remained third direct cause maternal deaths. These cases are preventable if policy is able to cope with the barriers of sexual and reproductive health of developing worlds. The government's safe motherhood strategies and free delivery policies has gradually increased the percentage of institutional delivery cases. It was 41.4 per cent in 2001 and rose to 58.7 per cent in 2016 and 77.5 per cent women age 15-49 years with live birth in the last two years whose most recent live birth was delivered in health facilities (CBS, 2020).

Use of contraception is a healthy way to maintain sound sexual and reproductive health that can prevent unintended pregnancies and early child bearing and its consequences. In Nepal, though universal knowledge of family planning among adolescent, Nepal Demographic Health Survey reveals that only nearly 15 per cent married adolescent (15-19) are currently using modern contraceptives. It is slowly 


\section{Adolescent Health: Changing Over Time in Nepal}

increased over time from 4.4 per cent in 1996 but this level is far below compared to age $15-49$ years 43 per cent.

Most of the indicators of maternal health care have been improved over past 20 years. The adolescent women received antenatal care form skilled provider was nearly 53 per cent in 1996 which had increased to 87 per cent in 2016. It was 84 per cent in 2016 for overall reproductive age group. It shows that adolescent mothers are more aware and likely to ANC visit compared to older ages (Table 1). The practice of early marriage and child bearing is common in Nepal but decreasing over time very slowly. Ministry of Health and Population, 2017 points out that among girls 15-19 years, 27 per cent are already married and 17 per cent are already mothers or pregnant. It is much higher of our neighbouring countries India $(8 \%)$ and Pakistan $(8 \%)$. First population policy was formally initiated during third plan period (196-70), after the first World Population Conference organized by the United Nations in 1974. A taskforce on population was appointed to develop comprehensive population policy by National Planning Commission (NPC) for fifth five-year plan of Nepal. Likewise, First 15 years long term health plan (1975-90) and in 1975 and second 20 years long term health plan 1997-2017 were set in 1997. Female health volunteer program which is acknowledged as one of the best approach globally was started in 1980. In early days, their role were to support family planning especially distributing contraceptives and pills to control births but later it is expanded with other health related programmes including programmes targeted to achieve millennium development goals. National health policy 2019 encouraged to the private sector investment in health care services. Through, private investment concentrated in urban areas focusing for curative service, it has promoted to the national health mechanism. While government of Nepal has set a long term target of replacement level of fertility by the end of $12^{\text {th }}$ plan (2010-13) cases of childbearing are proportionately concentrated to lower ages. It urges to divert the concerns more to the younger ages and their needs in terms of family planning services and reproductive and sexual health. Out of some strategies adopted by the National Health Policies 2017, "the health-services will be made more intensified in rural area, the marginalized groups of the urban areas are also included and balance services will be provided on the basis of equity" but in most of the cases poor reproductive health indicators are found in rural, marginalized and vulnerable age group (15-19).

\section{Conclusion}

Information, access of quality of contraception and its choices, legal provision on age at marriage and abortion and its effective implementation are the key factors to determine the sexual and reproductive health. Nepal Government has attempted to address global concept of emerging issues on reproductive health as concluded in regional and international forums. Modern CPR almost constant for some later years it is reflected by the satisfaction with modern methods that may be supportive reasons of access, quality and choices of contraceptives. As government of Nepal has been formulating and implementing plan, policy and strategies revising as internationally recognized issues related to youth and adolescent sexual and reproductive health but in the case of CPR is not reflected. Still early marriage is persisting in Nepalese society. It is lower for female compared to their counterpart which is the main cause of early sexual debut of females. And extra marital sexual intercourse is increasing over time among Nepalese males but it is statistically very low for female. It is expected that this situation of multiple sex partner more or less will be increased over time for both sex. But Causes of low level CPR and slow rate of declining of unmet need especially for adolescent and youth is logically challenging issue. On the other side, as a whole, some reproductive 


\section{Adolescent Health: Changing Over Time in Nepal}

indicators i.e. MMR, ANC, PNC, TFR shows the positive result of government efforts but still looks like unable to address the emerging issues of adolescent sexual and reproductive health as it is expected.

Periodically conducted NDHS and NMICS report major reproductive health indicators i.e. ANC and PNC visits, MMR, safe abortion service receivers, CPR and unmet needs for contraception are different according to respondents age, sex, place of residence, educational status and vulnerable groups from socio-economic view point. It urges that government focus should be diverted towards the implementation at grass root level finding out the barriers.

Legalization of abortion has attributed to the reduction of unintended pregnancies and early child bearing (legitimate/illegitimate birth). Large portion of adolescent still has not enough information on legal provision and places to obtain safe abortion services. Tendency of early marriage exists though legally it is restricted before 20 years of age. If policies and strategies can address properly to the issues of disparities in terms of residence, level of education and economic status, gender and age specific needs and focused to the implementation through bottom to top approach this partial achievement could be raised to the expected achievement of particular target group.

Policies and strategies related with population and reproductive and sexual health of Nepal are highly guided by international conferences conducted time to time which are being made to cope the existing and emerging issues, generally in international level but to reflect these as output it is necessary to consider the ground level of reality of diversity. Government has attempted to address the critical issues of adolescent with different tools from policy level to grass root implementation level. Policies and programmes as mentioned in NHS, ASRH NAHDS have focused mainly to ensure on adolescent friendly health services and their participation in each level. Naturally adolescent is the age that can adopt easily new trends of available advancement but facts are not as expected i.e. lower CPR and high unmet need for modern contraceptives and low level of information on places of safe abortion among adolescent. It clears the gaps between attempts and achievements. It seeks further more attempts to the quest for bridging gaps by the concern authorities.

\section{References}

CBS. (2020). Multiple Indicators Cluster Survey 2019. Kathmandu, Nepal: Central Bureau of Statistics, UNICEF Nepal.

Central Bureau of Statistics. (2015). Nepal Multiple Indicator Cluster Survey 2014, Final Report. Kathmandu, Nepal: Central Bureau of Statistics and UNICEF Nepal.

CBS. (2014). Population Monograph of Nepal. Nepal: Central Bureau of Statistics.

Darroch, J. E., Woog, V., Bankole, A., \& Ashford, L. S. (2016). Adding it up: costs and benefits of meeting the contraceptive needs of adolescents.

Ministry of Health and Population (MoHP). (2007). Nepal Demographic and Health Survey 2006. Nepal: Ministry of Health and Population, New ERA and ICF International.

Ministry of Health and Population (MoHP). (2012). Nepal Demographic and Health Survey 2011. Kathmandu: Ministry of Health, New ERA and ICF International, Nepal.

Ministry of Health and Population (MoHP). (2017). Nepal Demographic and Health survey 2016. Nepal: Ministry of Health and Population, New ERA and ICF International, Nepal.

MoH. (2000). National Adolescent Health and Strategy. Kathmandu: Family Health Division. 


\section{Adolescent Health: Changing Over Time in Nepal}

National Research Council and Institute of Medicine. (2005). Growing Up Global: The Changing transitions to adulthood in Developing Countries. Washington, DC: The National Academies Press.

Pathak, R. S. \& Pokharel, T. (2012). Sexual and reproductive health status of adolescents and youth in Nepal. Nepal Population Journal. 17(16), 131-133.

Shakya, D. (2018). Trends in Sexual Practices of Nepalese Youth over Time 2006-2016. Tribhuvan University Journal, 32(1), 185-196.

WHO/UNFPA/UNICEF, 1989 cited in MoH. (2000). National Adolescent Health Developing Strategy. Kathmandu: Family Health Division, Department of Health Service.

WHO. (2021, January 18). Adolescent and Young Adult Health. Retrieved from https://www.who.int/news-room/fact-sheets/detail/adolescents-health-risks-andsolutions

WHO. (2020). Adolescent Pregnancy. Retrieved from who.int: https://www.who.int/en/news-room/fact-sheets

WHO. (2018a). Strategic Guidance on Accelerating Actions for Adolescent Health in South East Asia Region (018-2022). World Health Organization Regional Office for South-East Asia.

WHO. (2018b, July 18). Nepal RMNCAH Factsheet July 2018. Retrieved from https://www.who.int/docs/default-source/reproductive-health/maternalhealth/rmncah-fs-nep.pdf?sfvrsn=b2ca04d5_2

World Health Organization (WHO). (2019). Maternal, newborn, child and adolescent heatlh. Retrieved from

https://www.who.int/maternal_child_adolescent/asolescence/universal-healthciverage/en/

World Health Organization. (2004). Maternal Mortality in 2000. Geneva. Geneva. 